\title{
A Cross-sectional Survey of an Ongoing Public Multimodal Intervention for Cognitive Health for Older Adults in Times of Covid-19
}

Barbara Studer-Luethi ( $\nabla$ barbara.studer@psy.unibe.ch )

University of Bern: Universitat Bern https://orcid.org/0000-0002-3428-9581

Maria Brasser

University of Zurich: Universitat Zurich

Simon Lusti

University of Bern: Universitat Bern

Rahel Schaerli

University of Bern: Universitat Bern

\section{Research}

Keywords: Cognitive health, public prevention, multimodal intervention, cognitive stimulation

Posted Date: March 11th, 2021

DOI: https://doi.org/10.21203/rs.3.rs-272279/v1

License: (9) (1) This work is licensed under a Creative Commons Attribution 4.0 International License. Read Full License 


\section{Abstract}

Background

In recent decades, the proportion of older adults in the population has continued to rise and with it the need for intervention programs to maintain cognitive functions into old age. Multiple lifestyle factors, first and foremost physical, cognitive, and social activities, have been shown to be crucial to forestalling decline in cognitive functions. However, since Covid-19 has curtailed opportunities for such activities, strategies must be designed to support older adults to remain cognitively healthy.

Methods

This study describes a newly developed ongoing publicly available preventive intervention, called brain coach, to support and stimulate cognitive activity in older adults. The intervention consists of weekly recommendations for evidence-based physical, cognitive, social, mindful, and creative activation exercises that can be integrated in daily life. 660 participants participated in an online cross-sectional survey examining experienced benefits and changes in relation to the program.

Results

Participants reported benefits in memory, well-being, attitudes towards the brain, and lifestyle habits. Importantly, time invested in the intervention as well as some characteristics of participants, such as personality and positive attitude toward brain health, show positive relationships with these experienced benefits. Further research will explore the effects of such a multimodal intervention in a longitudinal randomized controlled trial study.

\section{Background}

The ability to clearly think, learn, and remember is essential to performing everyday activities and living independently. Therefore, as we age, one important goal is to maintain this general cognitive health. Because the proportion of older individuals in the general population continues to increase (United Nations, 2019), the demand for effective programs that support individuals in preventing cognitive decline is also growing. The structure of the adult brain has a great capacity to adapt and change in response to experience and training (Colcombe et al., 2006), so preventative approaches are promising.

Encouragingly, research findings from the previous two decades have shown that cognitive decline is strongly influenced by nonbiological factors and lifestyle (Hedden \& Gabrieli, 2004): Several lifestyle changes are crucial for cognitive health, first and foremost physical, cognitive, and social activities. Regulations imposed in response to coronavirus disease of 2019 (Covid-19) have restricted various opportunities for such cognitively stimulating activities, such as cultural events and other social interactions. Thus, interventions that support and guide older adults in their daily cognitive activities are even more important to protect them from cognitive decline. This pilot study aims to evaluate an ongoing multimodal online intervention with a cross-sectional survey. The intervention raises older adults' awareness of the impact of their lifestyle on their cognitive health and sends them weekly exercise suggestions to support them in making cognitively stimulating activities part of their routine.

\section{Crucial lifestyle factors which prevent cognitive decline}

A growing body of scientific research and the resulting World Health Organization (WHO) guidelines (Astrup et al., 2019) have identified several crucial lifestyle factors that reduce the risk of cognitive decline and dementia.

The first factor is actively taking care of physical health, by healthy food intake (Morris et al., 2015) and regular physical exercise (Buchmann et al., 2019). Individuals who are obese in midlife have a higher risk of dementia than those of healthy body weight. Indeed, both healthy food and physical exercise modulate the cellular and molecular processes in the brain that are vital for cognitive health, including the optimization of growth factors such as brainderived neurotrophic factor (e.g., Chieffi et al., 2017). Intervention studies have shown that physical activity and optimized dietary behaviors increase cognitive functioning in older age and that greater physical activity is beneficial in protecting against cognitive decline (Schlaff et al., 2018).

The second factor is cognitive activity such as lifelong learning and intellectual engagement. Higher cognitive activity in midlife and later life is linked to delayed onset of cognitive impairment (Vemuri et al., 2014). Cognitive interventions aim either to train memory and other cognitive processes directly or to train memory strategies that in turn improve cognitive performance (Bottiroli et al., 2013). Findings regarding the effects of cognitive interventions on the general cognitive functions of older adults are inconclusive (for a recent review, see Sanjuán et al., 2020). Some cognitive interventions demonstrated significant benefits and even indicate some transfer to daily life in healthy older adults (Ball et al., 2002; Bottiroli et al., 2013; Tennstedt \& Unverzagt, 2013) or in older adults with mild cognitive impairments or dementia (Zhang \& Chignell, 2020). Other cognitive interventions produced no significant benefits on cognitive performance of older adults (e.g. Almond, Moulin \& Morrison, 2015).

Another crucial factor is social activity. Few social contacts and low social have both been associated with increased dementia risk (Kuiper et al., 2015). Research has confirmed the importance of social connection through social activities to protect from cognitive decline and reduce feelings of isolation and Ioneliness (see Cacioppo et al., 2015; Masi et al., 2011, for a meta-analysis). Various intervention studies have shown positive effect of social activities on cognitive variables (e.g., Bambini et al., 2020; Christelis \& Dobrescu, 2020, for a meta-analysis). For example, a study of older adults with dementia revealed the positive influence of communication with family members and healthcare professionals on patients' behavior and symptoms (Videler et al., 2020).

A range of other factors have also been found to influence cognitive function in older adults. One of them is mindfulness, which is associated with lower perceived stress and cortisol levels and with improve well-being (cf. Grossman et al., 2004). Because chronic stress is known to affect memory and increase the risk of dementia (McEwen, 2017), mindfulness-based interventions are thought to protect cognitive health (cf. Chiesa et al., 2011). In addition to this 
indirect effect on cognition through improved physiological mechanisms related to stress and immune function, a direct effect has been proposed through the repeated activation of attentional functions (Malinowski \& Shalamanova, 2017)). Indeed, evidence has shown that mindfulness-based interventions improve cognition in older adults both with and without mild cognitive impairment (Wells et al., 2019; Zhang et al., 2018).

Another factor is creativity, which is linked not only to mental and physiological health indicators but also to cognition in older age (e.g., Sharma \& Babu, 2017). Individuals that frequently engage in highly creative activities demonstrate higher cognitive reserve than individuals with more routine activities (Colombo et al., 2018). Intervention studies with older adults both with and without mild cognitive impairment or dementia found greater positive effects on cognitive functions and daily living ability after creative therapy (e.g. drawing, dance, music, story-telling) than after standard cognitive training (Martinec \& Lera, 2018; Zhao et al., 2018). In addition to interventions traditionally identified as creative, other creative activities include idea generation and improvising (cf. Flood \& Phillips, 2007).

Finally, humor leads to the release of endorphins in the brain and a reduction of cortisol, which produces psychological and physiological effects that are similar to the benefits of aerobic exercise (cf. Berk et al., 2001). Also, humor is a form of cognitive reappraisal, allowing individuals to reappraise daily stressors. Therefore, humor is suggested as an approach to decrease stress and protect cognitive abilities in older adults (cf. Mallya et al., 2018). Humor interventions have been shown to relieve chronic pain, and enhance happiness and life satisfaction (e.g. Tse et al., 2010).

In sum, research into cognitive health suggests that the effect of these activities on cognitive fitness may be additive. Consequently, a generally active lifestyle seems to be more effectual than specific short-term interventions (Kuster et al., 2016). Whereas single-component interventions often result in task-specific improvements with very little, if any, generalization to overall cognitive functioning and daily life situations (e.g. Hudes et al., 2019; Reijnders et al., 2013), multimodal interventions may produce greater benefits by addressing multiple factors (cf. Chalfont et al., 2020). For example, lifestyle interventions that combine physical exercise with cognitive training produce good results (Maffei et al., 2017; Ngandu et al., 2015).

The present cross-sectional study evaluates an ongoing public multimodal intervention that combines all of the evidence-based factors mentioned above to support older adults in their cognitive fitness and health. The intervention consists of weekly exercise recommendations for physical, cognitive, social, mindful, and creative activities for daily life combined with psychoeducational information about the impact of their lifestyle on their cognitive health. The purpose of the intervention was to encourage and instruct participants to make particular activities and specific exercises part of their daily activities. The aim of this cross-sectional study survey was to determine what kind of individuals participate in such a public intervention, how much time they spend on the exercises, and whether they experience any benefits from the intervention. Furthermore, we aimed to investigate how the characteristics of the participants and the time they invested influenced self-rated changes and lifestyle adaptations.

\section{Methods}

\section{Participants}

The intervention began in the German-speaking part of Switzerland in March, and the cross-section survey was conducted from August to October 2020. A total of 660 individuals participated in the study. Inclusion criteria were met when a participant used the intervention for personal reasons and exhibited an age minimum of 60 years, resulting in a total of 542 participants who were included in statistical analyses. Demographic data comprised age $(M=71.47, S D=$ 6.34 , range: $60-92)$, years of education $(M=13.80, S D=1.82$, range: $6-16)$, sex $(76.2 \%$ female), civil status ( $3.0 \%$ unmarried, $45.0 \%$ married, $9.0 \%$ divorced, $9.0 \%$ widowed, and $1.5 \%$ civil union), and health condition ( $47.5 \%$ very good, $48.6 \%$ rather good, $3.7 \%$ rather bad, and $0.3 \%$ bad).

\section{Procedure}

The free offer of a "brain coach" intervention was advertised in the online media. Individuals who registered for the intervention received a task sheet by email every week or every second week (length: approx. 2-5 pages). Participants were encouraged to implement the exercises and activities in their daily lives. They were free to choose which of the exercises they performed, when, and how intensely.

After 5 months, the online survey was sent by email to participants who had been part of the intervention for at least 3 months at the date of the evaluation. Participants completed the online survey anonymously.

\section{Intervention}

Every week or every second week, participants received a task sheet (3-6 pages) containing descriptions and links to short video demonstrations of various cognitive activation exercises for everyday life. The evidence-based exercises are designed to support cognitive health and addressed five areas: memory through cognitive training tasks and memory strategies such as N-back exercises and the loci method, coordination through physical coordination tasks such as balance and juggling exercises, mindfulness through exercises for increased self-awareness such as a breathing task, creativity through enhancement of creative processes such as connecting unrelated things, community through ideas for social activities without physical contact due to Covid-19, and humor through funny jokes and cartoons. In addition, the task sheets included psychoeducational information about brain functions and neuroplasticity as well as explanations about the effects of the exercises and strategies on neural processes and cognitive health.

\section{Self-reported measures}

\section{Characteristics of participants}

Personality. The Big Five Inventory, a 10 item questionnaire that records responses on 5-point Likert scales (Rammstedt \& John, 2007) was used as a measure of personality traits. 
Attitude towards the aging brain. Participants' attitudes toward their aging brains were assessed with a questionnaire designed by the authors and including five questions. One question assessed general belief in neuroplasticity, and the other four questions assessed the strength of positive and negative attitudes towards the aging brain on Likert scales ranging from 1 (no, not at all) to 4 (yes, a lot):

Belief in neuroplasticity. Participants' belief in their aging brains' plasticity was assessed with the question "What do you think about your aging brain?" Responses were recorded on an open scale ranging from 0 (age-dependent cognitive decline) to 10 (brain stays adaptive and capable).

Positive attitude. The strength of positive attitude (confidence in conserved learning ability) was calculated from the mean value for the general conviction about the plasticity of the brain and personal confidence in being able to positively influence cognitive fitness.

Negative attitude. The strength of negative attitude (worry about cognitive decline) was defined by calculating the mean value of general worries about biological, age-dependent cognitive decline and individual concerns about experienced decline in learning and memory.

\section{Intervention commitment}

The frequency with which exercises were performed was assessed with the question "How regularly do you perform exercises from the Hirncoach-program on average?" Five answer options were available, ranging from "less than every other week" to "daily."

The weekly time invested in the exercises was assessed with the question "How much time do you spend weekly on average doing exercises from the Hirncoach program?" The five answer options ranged from "less than 15 min a week" to "more than 2 hours a week."

The overall time invested for the intervention was calculated by multiplying the time invested in the intervention per week by the number of weeks since the individual date of registration.

\section{Perceived intervention-induced benefit}

Benefit in cognitive fitness: Participants were asked about the perceived effect of the intervention on their memory performance ("Have you experienced any benefit from the Hirncoach exercises for your cognitive fitness, such as memory?").

Benefit in well-being. Participants were asked about the perceived effect of the intervention on their well-being ("Have you experienced any benefit from the Hirncoach exercises for your well-being, such as mindfulness, so far?").

Benefit in brain health-related attitude. Participants were asked whether the intervention changed their attitude toward their brain health ("Have the Hirncoach exercises changed your attitude towards your brain health?").

Benefit in activities: Participants were asked whether the intervention changed their behavior ("Have you changed any activities that benefit the brain or body in everyday life because of the intervention?').

All answers were given on a Likert scale ranging from 1 (no) to 4 (yes, a lot).

\section{Data Analysis}

Descriptive statistical analyses were performed as mean and standard deviation and as frequency distribution for the sample characteristics, intervention commitment, and self-reported benefit of intervention. Correlation analyses were performed to analyze the relationship between participants' characteristics (belief in neuroplasticity, attitude towards brain health, personality), intervention commitment (total time investment), and self-reported benefits through the intervention (change in memory, mindfulness, attitude, activities). Kendall-Tau-b and Spearman coefficients of correlation were used, but for clarity only results from the former are reported. Finally, analysis of multiple linear regressions was performed with the dependent variable generalized experienced benefit, defined by the average of experienced effects on cognitive fitness and well-being and on brain-health-related attitude and behavior, and the two independent variables time investment and belief in neuroplasticity to analyze the variance and the strength of their relationships.

\section{Results}

Descriptive results and frequency distributions of sample characteristics, intervention commitment, and self-reported benefit are shown in Table 1 and Figs. 13. Correlations between these variables are shown in Table 1.

\section{Sample characteristics}

On average, participants used the intervention twice per week (see Figure 1). The average days of participation was $135.04(S D=36.75)$. The average of hours invested related to the intervention was $22.31(S D=28.13)$ and the mean of weekly invested hours related to the intervention was $0.65(S D=0.72 ;$ see Figure 2). Participants described the experienced benefit of intervention as "pretty much" on the four-point Likert Scale $(M=3.04, S D=0.56$; see Figure 3$)$, with the highest benefit on the attitude towards brain health $(M=3.14, S D=0.78)$.

\section{Personality is related to attitude towards aging brain and time investment}

Of the Big Five dimensions of personality, conscientiousness and agreeableness $(r=.14, r=.12$, respectively, both $p<.01)$ as well as extraversion and openness (both $r=.09, p<.05$ ) were positively related with time invested in the intervention, whereas neuroticism was negatively related, $r=-.10, p<.01$. The 
same pattern was found for the association with belief in neuroplasticity. By contrast, neuroticism showed a positive association with worries about cognitive decline, $r=.12, p<.01$, whereas conscientiousness, extraversion, and openness showed a negative association $(r=-.16, r=-.12, r=-.08$, respectively).

\section{Time invested in the intervention is related to self-reported benefit}

There was a significant relationship between time invested and benefit experienced in cognitive fitness, $r=.26, p<.01$; well-being, $r=.26, p<.01$; attitude, $r=$ $.20, p<.01$; and activity, $r=.29, p<.01$.

\section{Belief in neuroplasticity and positive attitudes are related to self-reported benefit}

The belief in neuroplasticity was significantly related to benefit experienced in cognitive fitness, $r=.18, p<.01$; well-being, $r=.14, p<.01$; attitude, $r=.15, p<$ .01 ; activity, $r=.10, p<.05$; and time investment, $r=.23, p<.01$.

Concerning the regression analyses with general experienced benefit as dependent variable and both time invested and belief in neuroplasticity as independent variables, a significant regression equation was found $(\mathrm{F}(2,357)=34.737, p<.000)$, with an $R^{2}$ of .093 . Participants' general experienced benefit increased by 0.01 rating points for each hour of investment and by 0.136 for each rating point of belief in neuroplasticity. Both time investment and belief in neuroplasticity were significant predictors of generalized benefit experienced.

\section{Discussion}

There is increasing scholarly support for the view that cognitive health is positively related to an active lifestyle that integrates physical, cognitive, and social activities. Restrictions imposed in response to Covid-19 have dramatically reduced older adults' opportunities for such stimulating activities in their daily lives. To forestall cognitive decline, a multimodal intervention is offered publicly. It informs participants about the impact of their lifestyle on their cognitive health and sends them weekly suggestions for evidence-based exercises that strengthen cognitive health. It also encourages them to make cognitively stimulating activities part of their daily routine with recommendations related to lifestyle factors shown to be crucial for cognitive health. This cross-sectional study aimed to assess commitment to this intervention and benefit experienced from it. We were interested in what kind of individuals participate in such a public intervention, how much time they spend on the exercises, and whether they experience any effects from the intervention. Furthermore, we aimed to investigate how the participants' characteristics and time invested relate to self-rated changes and lifestyle adaptations.

\section{Characteristics of participants}

The mean age of participants was 71 years. This is in line with the finding that older people's worries about their memory and dementia is highest around the age of 70 (see Bowen et al., 2019). However, recent review found inconclusive results about the influence of age on worries about dementia (see Werner et al., 2021).

Three quarters of the participants were female. This is comparable with memory and health intervention studies, where $79 \%$ or even $82 \%$ of at-risk older participants were female (McDougall et al., 2010; Settersten \& Lauver, 2004). Other findings confirm that women are more concerned about their health and about developing dementia, engage in more health-promoting behaviors, and seek preventive healthcare measures more often (see Pinkhasov et al., 2010 , for a review). Some explanations that could account for such gender differences are women's greater willingness and ability to take care of themselves when they are sick, several stereotypical masculine behaviors, and men's inclination to self-reliance, physical toughness, and emotional control (cf. Pinkhasov et al., 2010). However, there is as yet no consensus regarding whether men or women benefit more from interventions (see Barha et al., 2017; Stern et al., 2007, for reviews). Our sample showed no difference between males and females in intervention-related benefits $(t(367)=0.70, p>.05$.).

More than $90 \%$ of the participants were in rather good or good health. This is not surprising because the intervention was noncommittal and online. Consequently, only individuals with access to internet and sufficient mental and self-regulation resources to implement the exercises independently were able to participate. Other research has demonstrated that perceived health status influences participation in health promotion behaviors (Settersten \& Lauver, 2004).

\section{Intervention commitment}

The average weekly time invested in exercises was around 50 minutes, performed on average twice per week. This suggests that intervention commitment was quite high and confirms the animating effect of the intervention. It is also in line with other interventions in older adults, which elicited between one and three home exercise sessions per week on average (cf. Picorelli et al., 2014), and it corresponds to the suggested intensity of lifestyle intervention activities (Klimova et al., 2017).

\section{Self-reported perceived benefits and time investment}

Around $60 \%$ of the participants estimated that they benefitted substantially from the intervention and more than $25 \%$ reported very high benefit. Because this survey was cross-sectional, retrospective bias cannot be excluded, and no causal interpretation can be made. Nevertheless, the result suggests that participants experienced positive effects from the exercises introduced in the intervention. Importantly, this assumption is supported by the finding that selfreported benefits were closely related to the time invested in intervention-related exercises. This confirms that the higher the investment in active lifestyle, the higher the benefits experienced over time (cf. Kuster et al., 2016).

Participants experienced comparable positive effects on their memory performance, well-being, attitude towards their brain health, and activities in daily life. This confirms that interventions integrating recommendations and instructions of evidence-based exercises and lifestyle activities for cognitive health can 
exert a positive effect not only on cognition but also on well-being, attitude, and lifestyle activities (e.g. Hudes et al., 2019; Klimova et al., 2017; Ng et al., 2017).

Relationship between personality, attitude towards brain health, and time investment

Except neuroticism, all of the big five personality factors were positively related to participants' belief in neuroplasticity. In contrast, neuroticism was related to higher worries about cognitive decline. This is in line with findings of a positive correlation between neuroticism and dementia worry (e.g. Furr, 2018).

Furthermore, neuroticism was negatively related to time invested in intervention-related activities, whereas the other personality traits were positively related to this factor. The associations of both positive attitude and intervention commitment with conscientiousness were the strongest among the personality traits, which is in line with the finding that higher conscientiousness is associated with lower dementia risk (Kaup et al., 2019). Our findings suggest that personality may influence attitudes towards both the aging brain and the importance of lifestyle interventions to older adults. In particular, individuals with high neuroticism can be encouraged by providing them with information about the brain's capacity for plasticity and the impact of active lifestyles on cognitive health.

Individuals with stronger belief in neuroplasticity indicated greater time investment in the intervention-related exercises and reported higher benefit experienced in cognitive fitness, well-being, attitude, and activity. This is in line with studies demonstrating that individuals with positive age stereotypes show less and slower cognitive decline than individuals with negative stereotypes (Levy et al., 2016; 2012). Positive attitude to brain health seems to promote the willingness and motivation to invest in healthy behaviour and to protect cognitive health.

\section{Limitations and outlook}

The main limitation of this study is the cross-sectional method, which precludes any conclusions about causalities and intervention effects. Also, all measures were self-reported and therefore prone to bias and social desirability.

Future research should conduct more longitudinal randomized control trials with large samples of subjects to evaluate the effects of lifestyle interventions applied at different stages of life. Such public lifestyle interventions should effectively communicate scientific evidence about the impact of an active lifestyle, especially physical, cognitive, social, mindful, and creative activities, on preventing cognitive decline.

\section{Conclusions And Implications}

This ongoing public intervention, which is offered to older adults to support them in maintaining their cognitive health, follows Williams and Camper`s (2010) appeal that "older adults may be advised to add new cognitive, physical, and social activities, and improved nutrition to support successful cognitive aging and to improve neuroplasticity." The present multimodal lifestyle intervention includes recommendations for such evidence-based activities, lifestyle advice, and background information about the aging brain. It is of considerable length and tailored to life circumstances that have changed in the Covid-19 pandemic. This cross-sectional survey suggests the benefits of the intervention on memory, well-being, positive attitude toward the aging brain, and the lifestyles of older adults. Importantly, booth time investment and participants belief in neuroplasticity were positively related to experienced intervention benefit.

The present analyses highlight the potential of public multimodal health intervention and psychoeducation to motivate older adults to change their health behavior. Specifically, the data reveal the importance of participants' attitudes toward brain health to their investment in behavior that protects cognitive health. Moreover, it seems important at a societal level to find ways to promote positive age stereotypes and attitudes towards the aging brain.

Neuropsychoeducative information, such as about the neuroplasticity of the aging brain, should always be part of cognitive intervention and health programs. Being aware of the brain's capacity for plasticity and the resulting importance of everyday activities may motivate people to adopt and maintain healthier lifestyles and thus reduce or even prevent cognitive decline and dementia. To maximize the utility of such lifestyle interventions, recommendations could be personalized to participants' lifestyles and attitudes towards brain health (cf. Barha et al., 2017). Furthermore, public lifestyle interventions should be implemented as early as possible to support the protection of older adults' health and brains before impairment occurs.

In sum, the results of this cross-sectional survey indicate that this public multimodal intervention animated participating older adults to invest in their cognitive health and that resulting benefits were experienced in daily lives.

\section{Abbreviations}

Covid-19: coronavirus disease of 2019

WHO: World Health Organization

\section{Declarations}

\section{Ethics approval and consent to participate}

The ethics committee of the University of Bern has approved the study. The ethic committee's Uni Approval Code is 2015-3-1213381.

All participants agreed at the beginning of the questionnaire to give their answers anonymously.

\section{Consent for publication}

Not applicable 


\section{Availability of data and materials}

The datasets used and analysed during the current study are available from the corresponding author on reasonable request.

\section{Competing interests}

There is no commercial interest in the described intervention, therefore no conflict of interest to declare.

\section{Funding}

No fundings.

\section{Authors' contributions}

BSL: data collection and writing of the manuscript

RS: data collection, literature research, method description

MB: literature research, writing of the manuscript

SL: statistical analyses and writing of results

\section{Acknowledgements}

We thank Prof. Dr. Martin Meyer for his consultation.

\section{References}

1. Almond, N. M., Moulin, C. J., \& Morrison, C. (2015). Objective and Subjective Measures of Performance in Older Adults Undergoing a Cognitive Activity Intervention. Healthy Aging Research 4:3. Foi:10.12715/har.4.3

2. Astrup, A., Bertram, H. C., Bonjour, J. P., de Groot, L. C., de Oliveira Otto, M. C., Feeney, E. L., Garg, M. L., Givens, I., Kok, F. J., Krauss, R. M., Lamarche, B., Lecerf, J. M., Legrand, P., McKinley, M., Micha, R., Michalski, M. C., Mozaffarian, D., \& Soedamah-Muthu, S. S. (2019, Jul 3). WHO draft guidelines on dietary saturated and trans fatty acids: time for a new approach? BMJ, 366, 14137. https://doi.org/10.1136/bmj.14137

3. Ball, K., Berch, D. B., Helmers, K. F., Jobe, J. B., Leveck, M. D., Marsiske, M., Morris, J. N., Rebok, G. W., Smith, D. M., \& Tennstedt, S. L. (2002). Effects of cognitive training interventions with older adults: a randomized controlled trial. Jama, 288(18), 2271-2281.

4. Bambini, V., Tonini, E., Ceccato, I., Lecce, S., Marocchini, E., \& Cavallini, E. (2020, Dec). How to improve social communication in aging: Pragmatic and cognitive interventions. Brain Lang, 211, 104864. https://doi.org/10.1016/j.bandl.2020.104864

5. Barha, C. K., Falck, R. S., Davis, J. C., Nagamatsu, L. S., \& Liu-Ambrose, T. (2017, Jul). Sex differences in aerobic exercise efficacy to improve cognition: A systematic review and meta-analysis of studies in older rodents. Front Neuroendocrinol, 46, 86-105. https://doi.org/10.1016/j.yfrne.2017.06.001

6. Berk, L. S., Felten, D. L., Tan, S. A., Bittman, B. B., \& Westengard, J. (2001, Mar). Modulation of neuroimmune parameters during the eustress of humorassociated mirthful laughter. Altern Ther Health Med, 7(2), 62-72, 74-66. https://www.ncbi.nlm.nih.gov/pubmed/11253418

7. Bottiroli, S., Cavallini, E., Dunlosky, J., Vecchi, T., \& Hertzog, C. (2013, Sep). The importance of training strategy adaptation: a learner-oriented approach for improving older adults' memory and transfer. J Exp Psychol Appl, 19(3), 205-218. https://doi.org/10.1037/a0034078

8. Bowen, C. E., Kessler, E. M., \& Segler, J. (2019, Mar). Dementia worry in middle-aged and older adults in Germany: sociodemographic, health-related and psychological correlates. Eur J Ageing, 16(1), 39-52. https://doi.org/10.1007/s10433-018-0462-7

9. Buchmann, N., Spira, D., Konig, M., Demuth, I., \& Steinhagen-Thiessen, E. (2019). Frailty and the Metabolic Syndrome - Results of the Berlin Aging Study II (BASE-II). J Frailty Aging, 8(4), 169-175. https://doi.org/10.14283/jfa.2019.15

10. Cacioppo, J. T., Adler, A. B., Lester, P. B., McGurk, D., Thomas, J. L., Chen, H. Y., \& Cacioppo, S. (2015, Jul). Building social resilience in soldiers: A double dissociative randomized controlled study. J Pers Soc Psychol, 109(1), 90-105. https://doi.org/10.1037/pspi0000022

11. Chalfont, G., Milligan, C., \& Simpson, J. (2020, May). A mixed methods systematic review of multimodal non-pharmacological interventions to improve cognition for people with dementia. Dementia (London), 19(4), 1086-1130. https://doi.org/10.1177/1471301218795289

12. Chieffi, S., Messina, G., Villano, I., Messina, A., Esposito, M., Monda, V., Valenzano, A., Moscatelli, F., Esposito, T., Carotenuto, M., Viggiano, A., Cibelli, G., \& Monda, M. (2017). Exercise Influence on Hippocampal Function: Possible Involvement of Orexin-A. Front Physiol, 8, 85. https://doi.org/10.3389/fphys.2017.00085

13. Chiesa, A., Calati, R., \& Serretti, A. (2011, Apr). Does mindfulness training improve cognitive abilities? A systematic review of neuropsychological findings Clin Psychol Rev, 31(3), 449-464. https://doi.org/10.1016/j.cpr.2010.11.003

14. Christelis, D., \& Dobrescu, L. I. (2020, Jan 9). The causal effect of social activities on cognition: Evidence from 20 European countries. Soc Sci Med, 247 112783. https://doi.org/10.1016/j.socscimed.2020.112783

15. Colcombe, S. J., Erickson, K. I., Scalf, P. E., Kim, J. S., Prakash, R., McAuley, E., Elavsky, S., Marquez, D. X., Hu, L., \& Kramer, A. F. (2006, Nov). Aerobic exercise training increases brain volume in aging humans. J Gerontol A Biol Sci Med Sci, 61(11), 1166-1170. https://doi.org/10.1093/gerona/61.11.1166

16. Colombo, B., Antonietti, A., \& Daneau, B. (2018). The Relationships Between Cognitive Reserve and Creativity. A Study on American Aging Population. Front Psychol, 9, 764. https://doi.org/10.3389/fpsyg.2018.00764 
17. Flood, M., \& Phillips, K. D. (2007, Apr). Creativity in older adults: a plethora of possibilities. Issues Ment Health Nurs, 28(4), $389-411$. https://doi.org/10.1080/01612840701252956

18. Furr, E. (2018). EXAMINING PERSONALITY AND DEMENTIA WORRY AMONG MIDDLE-AGED AND OLDER ADULTS. Innovation in Aging, 2(Suppl 1), 110110. https://doi.org/10.1093/geroni/igy023.409

19. Grossman, P., Niemann, L., Schmidt, S., \& Walach, H. (2004, Jul). Mindfulness-based stress reduction and health benefits. A meta-analysis. J Psychosom Res, 57(1), 35-43. https://doi.org/10.1016/S0022-3999(03)00573-7

20. Hedden, T., \& Gabrieli, J. D. (2004, Feb). Insights into the ageing mind: a view from cognitive neuroscience. Nat Rev Neurosci, 5(2), 87-96. https://doi.org/10.1038/nrn1323

21. Hudes, R., Rich, J. B., Troyer, A. K., Yusupov, I., \& Vandermorris, S. (2019, Jun). The impact of memory-strategy training interventions on participantreported outcomes in healthy older adults: A systematic review and meta-analysis. Psychol Aging, 34(4), 587-597. https://doi.org/10.1037/pag0000340

22. Kaup, A. R., Harmell, A. L., \& Yaffe, K. (2019). Conscientiousness Is Associated with Lower Risk of Dementia among Black and White Older Adults. Neuroepidemiology, 52(1-2), 86-92. https://doi.org/10.1159/000492821

23. Klimova, B., Valis, M., \& Kuca, K. (2017). Cognitive decline in normal aging and its prevention: a review on non-pharmacological lifestyle strategies. Clin Interv Aging, 12, 903-910. https://doi.org/10.2147/CIA.S132963

24. Kuiper, J. S., Zuidersma, M., Oude Voshaar, R. C., Zuidema, S. U., van den Heuvel, E. R., Stolk, R. P., \& Smidt, N. (2015, Jul). Social relationships and risk of dementia: A systematic review and meta-analysis of longitudinal cohort studies. Ageing Res Rev, 22, 39-57. https://doi.org/10.1016/j.arr.2015.04.006

25. Kuster, O. C., Fissler, P., Laptinskaya, D., Thurm, F., Scharpf, A., Woll, A., Kolassa, S., Kramer, A. F., Elbert, T., von Arnim, C. A., \& Kolassa, I. T. (2016, Sep 8). Cognitive change is more positively associated with an active lifestyle than with training interventions in older adults at risk of dementia: a controlled interventional clinical trial. BMC Psychiatry, 16(1), 315. https://doi.org/10.1186/s12888-016-1018-z

26. Levy, B. R., Ferrucci, L., Zonderman, A. B., Slade, M. D., Troncoso, J., \& Resnick, S. M. (2016, Feb). A culture-brain link: Negative age stereotypes predict Alzheimer's disease biomarkers. Psychol Aging, 31(1), 82-88. https://doi.org/10.1037/pag0000062

27. Levy, B. R., Zonderman, A. B., Slade, M. D., \& Ferrucci, L. (2012, Jul). Memory shaped by age stereotypes over time. J Gerontol B Psychol Sci Soc Sci, 67(4), 432-436. https://doi.org/10.1093/geronb/gbr120

28. Maffei, L., Picano, E., Andreassi, M. G., Angelucci, A., Baldacci, F., \& Baroncelli. (2017, Jan 3). Randomized trial on the effects of a combined physical/cognitive training in aged MCl subjects: the Train the Brain study. Scientific reports, 7, 39471. https://doi.org/10.1038/srep39471

29. Malinowski, P., \& Shalamanova, L. (2017, 2017/06/01). Meditation and Cognitive Ageing: the Role of Mindfulness Meditation in Building Cognitive Reserve. Journal of Cognitive Enhancement, 1(2), 96-106. https://doi.org/10.1007/s41465-017-0022-7

30. Mallya, S., Reed, M., \& Yang, L. (2018). A theoretical framework for using humor to reduce the effects of chronic stress on cognitive function in older adults: An integration of findings and methods from diverse areas of psychology. HUMOR, 32, 49 - 71.

31. Martinec, R., \& Lera, K. (2018). Movement, Music and Creativity in The Elderly with Dementia. Gerontology \& Geriatrics Studies, 4(2). https://doi.org/10.31031/GGS.2018.04.000585

32. Masi, C. M., Chen, H. Y., Hawkley, L. C., \& Cacioppo, J. T. (2011, Aug). A meta-analysis of interventions to reduce loneliness. Pers Soc Psychol Rev, 15(3), 219-266. https://doi.org/10.1177/1088868310377394

33. McDougall, G. J., Jr., Becker, H., Pituch, K., Acee, T. W., Vaughan, P. W., \& Delville, C. L. (2010, Oct). The SeniorWISE study: improving everyday memory in older adults. Arch Psychiatr Nurs, 24(5), 291-306. https://doi.org/10.1016/j.apnu.2009.11.001

34. McEwen, B. S. (2017, Jun 1). Allostasis and the Epigenetics of Brain and Body Health Over the Life Course: The Brain on Stress. JAMA Psychiatry, 74(6), 551-552. https://doi.org/10.1001/jamapsychiatry.2017.0270

35. Morris, M. C., Tangney, C. C., Wang, Y., Sacks, F. M., Bennett, D. A., \& Aggarwal, N. T. (2015, Sep). MIND diet associated with reduced incidence of Alzheimer's disease. Alzheimers Dement, 11(9), 1007-1014. https://doi.org/10.1016/j.jalz.2014.11.009

36. Ng, T. P., Nyunt, M. S. Z., Feng, L., Feng, L., Niti, M., Tan, B. Y., Chan, G., Khoo, S. A., Chan, S. M., Yap, P., \& Yap, K. B. (2017). Multi-Domains Lifestyle Interventions Reduces Depressive Symptoms among Frail and Pre-Frail Older Persons: Randomized Controlled Trial. J Nutr Health Aging, $21(8), 918-926$. https://doi.org/10.1007/s12603-016-0867-y

37. Ngandu, T., Lehtisalo, J., Solomon, A., Levalahti, E., Ahtiluoto, S., Antikainen, R., Backman, L., Hanninen, T., Jula, A., Laatikainen, T., Lindstrom, J., Mangialasche, F., Paajanen, T., Pajala, S., Peltonen, M., Rauramaa, R., Stigsdotter-Neely, A., Strandberg, T., Tuomilehto, J., Soininen, H., \& Kivipelto, M. (2015, Jun 6). A 2 year multidomain intervention of diet, exercise, cognitive training, and vascular risk monitoring versus control to prevent cognitive decline in at-risk elderly people (FINGER): a randomised controlled trial. Lancet, 385(9984), 2255-2263. https://doi.org/10.1016/S0140-6736(15)60461-5

38. Picorelli, A. M., Pereira, L. S., Pereira, D. S., Felicio, D., \& Sherrington, C. (2014, Sep). Adherence to exercise programs for older people is influenced by program characteristics and personal factors: a systematic review. J Physiother, 60(3), 151-156. https://doi.org/10.1016/j.jphys.2014.06.012

39. Pinkhasov, R. M., Wong, J., Kashanian, J., Lee, M., Samadi, D. B., Pinkhasov, M. M., \& Shabsigh, R. (2010, Mar). Are men shortchanged on health? Perspective on health care utilization and health risk behavior in men and women in the United States. Int J Clin Pract, 64(4), $475-487$.

https://doi.org/10.1111/j.1742-1241.2009.02290.x

40. Rammstedt, B., \& John, O. P. (2007). Measuring personality in one minute or less: A 10-item short version of the Big Five Inventory in English and German. Journal of Research in Personality, 41(1), 203-212.

41. Reijnders, J., van Heugten, C., \& van Boxtel, M. (2013, Jan). Cognitive interventions in healthy older adults and people with mild cognitive impairment: a systematic review. Ageing Res Rev, 12(1), 263-275. https://doi.org/10.1016/j.arr.2012.07.003 
42. Sanjuán, M., Navarro, E., \& Calero, M. D. (2020). Effectiveness of Cognitive Interventions in Older Adults: A Review. European Journal of Investigation in Health, Psychology and Education, 10 (3), 2254-9625. https://doi.org/DO - 10.3390/ejihpe10030063

43. Schlaff, R. A., Baruth, M., Adams, V. J., Goldufsky, T. M., Peters, N. A., Kerr, G., Boggs, A., \& Ewald, A. (2018, Jan). Effects of a Group-Based Behavioral Intervention on Dietary Behaviors in Older Adults. J Aging Health, 30(1), 105-117. https://doi.org/10.1177/0898264316668936

44. Settersten, L., \& Lauver, D. R. (2004, Jan-Feb). Critical thinking, perceived health status, and participation in health behaviors. Nurs Res, 53(1), 11-18. https://doi.org/10.1097/00006199-200401000-00002

45. Sharma, S., \& Babu, N. (2017, 2017/01/02). Interplay between Creativity, Executive Function and Working Memory in Middle-Aged and Older Adults. Creativity Research Journal, 29(1), 71-77. https://doi.org/10.1080/10400419.2017.1263512

46. Stern, A., Laughlin, G. A., Bergstrom, J., \& Barrett-Connor, E. (2007, May). The sex-specific association of serum osteoprotegerin and receptor activator of nuclear factor kappaB legend with bone mineral density in older adults: the Rancho Bernardo study. Eur J Endocrinol, 156(5), 555-562. https://doi.org/10.1530/EJE-06-0753

47. Tennstedt, S. L., \& Unverzagt, F. W. (2013, Dec). The ACTIVE study: study overview and major findings. J Aging Health, 25(8 Suppl), 3 S-20S. https://doi.org/10.1177/0898264313518133

48. Tse, M. M., Lo, A. P., Cheng, T. L., Chan, E. K., Chan, A. H., \& Chung, H. S. (2010, Jun 28). Humor therapy: relieving chronic pain and enhancing happiness for older adults. J Aging Res, 2010, 343574. https://doi.org/10.4061/2010/343574

49. United Nations, Department of Economic and Social Affairs, Population Division (2019). World Population Ageing 2019: Highlights (ST/ESA/SER.A/430).

50. Vemuri, P., Lesnick, T. G., Przybelski, S. A., Machulda, M., Knopman, D. S., Mielke, M. M., Roberts, R. O., Geda, Y. E., Rocca, W. A., Petersen, R. C., \& Jack, C. R., Jr. (2014, Aug). Association of lifetime intellectual enrichment with cognitive decline in the older population. JAMA Neurol, 71(8), 1017-1024. https://doi.org/10.1001/jamaneurol.2014.963

51. Videler, A. C., Heijnen-Kohl, S. M. J., Wilting, R., \& van Alphen, S. P. J. (2020, Jun 4). [Differential diagnosis personality disorder versus autism spectrum disorder in older adults]. Tijdschr Gerontol Geriatr, 51(2). https://doi.org/10.36613/tgg.1875-6832/2020.02.04 (Differentiele diag\&shy;nostiek van persoonlijk\&shy;heids\&shy;stoornissen en autisme\&shy;spectrum\&shy;stoornis bij ouderen.)

52. Wells, R. E., Kerr, C., Dossett, M. L., Danhauer, S. C., Sohl, S. J., Sachs, B. C., Feeley, J. W., Wolkin, J., Wall, R., Kaptchuk, T., Press, D. Z., Phillips, R. S., \& Yeh, G. Y. (2019). Can Adults with Mild Cognitive Impairment Build Cognitive Reserve and Learn Mindfulness Meditation? Qualitative Theme Analyses from a Small Pilot Study. J Alzheimers Dis, 70(3), 825-842. https://doi.org/10.3233/JAD-190191

53. Werner, P., AboJabel, H., \& Maxfield, M. (2021, Jan - Feb). Conceptualization, measurement and correlates of dementia worry: A scoping review. Arch Gerontol Geriatr, 92, 104246. https://doi.org/10.1016/j.archger.2020.104246

54. Williams, K. N., \& Kemper, S. (2010, May). Interventions to reduce cognitive decline in aging. J Psychosoc Nurs Ment Health Serv, 48(5), $42-51$. https://doi.org/10.3928/02793695-20100331-03

55. Zhang, B., \& Chignell, M. H. (2020). Flattening the Curve of Cognitive Decline: A Survey of Cognitive Interventions for People Living with Dementia. Proceedings of the International Symposium on Human Factors and Ergonomics in Health Care, 9(1), 110-114. https://doi.org/10.1177/2327857920091064

56. Zhang, Y., Li, C., Zou, L., Liu, X., \& Song, W. (2018, Dec 9). The Effects of Mind-Body Exercise on Cognitive Performance in Elderly: A Systematic Review and Meta-Analysis. Int J Environ Res Public Health, 15(12). https://doi.org/10.3390/ijerph15122791

57. Zhao, J., Li, H., Lin, R., Wei, Y., \& Yang, A. (2018). Effects of creative expression therapy for older adults with mild cognitive impairment at risk of Alzheimer's disease: a randomized controlled clinical trial. Clin Interv Aging, 13, 1313-1320. https://doi.org/10.2147/CIA.S161861

\section{Table}


Descriptive Statistics and Correlations for Benefits Experienced, Time Investment, Attitudes, and Big Five Personality Traits

\begin{tabular}{|c|c|c|c|c|c|c|c|c|c|c|c|c|c|c|}
\hline Variables & $M$ & SD & 1 & 2 & 3 & 4 & 5 & 6 & 7 & 8 & 9 & 10 & 11 & 12 \\
\hline $\begin{array}{l}\text { 1. Cognitive } \\
\text { Fitness }^{a}\end{array}$ & 3.01 & 0.61 & - & & & & & & & & & & & \\
\hline 2. Well-being ${ }^{a}$ & 3.05 & 0.75 & $.43^{\star \star}$ & - & & & & & & & & & & \\
\hline 3. Attitude ${ }^{a}$ & 3.14 & 0.78 & $.34^{\star \star}$ & $.31^{\star \star}$ & - & & & & & & & & & \\
\hline 4. Activity ${ }^{a}$ & 2.93 & 0.81 & $.40 * \star$ & $.40 * \star$ & $.42^{\star \star}$ & - & & & & & & & & \\
\hline $\begin{array}{l}\text { 5. Time } \\
\text { Investment }\end{array}$ & 22.31 & 28.13 & $.26 * \star$ & $.26^{\star \star}$ & $.20 * *$ & $.29 \star \star$ & - & & & & & & & \\
\hline $\begin{array}{l}\text { 6. Belief in } \\
\text { Neuroplasticity }\end{array}$ & 7.58 & 2.00 & $.18^{\star \star}$ & $.14^{\star \star}$ & $.15^{\star \star}$ & $.10 *$ & $.23^{\star \star}$ & & & & & & & \\
\hline $\begin{array}{l}\text { 7. Positive } \\
\text { Attitude }\end{array}$ & 3.24 & 0.57 & $.15^{\star \star}$ & $.13^{\star \star}$ & $.16^{\star \star}$ & $.27 \star \star$ & $.17^{\star \star}$ & $.07^{\text {n.s. }}$. & - & & & & & \\
\hline $\begin{array}{l}\text { 8. Negative } \\
\text { Attitude }\end{array}$ & 2.45 & 0.74 & $-.02^{\text {n.s }}$ & $.00^{\text {n.s. }}$. & $-.06^{\mathrm{n} . \mathrm{s}}$ & $.04^{\mathrm{n} . \mathrm{s}}$. & $-.06^{\mathrm{n} . \mathrm{s}}$ & -.41 ** & $.25^{\star \star}$ & - & & & & \\
\hline $\begin{array}{l}9 . \\
\text { Consciousness }\end{array}$ & 4.00 & 0.73 & $.05^{\mathrm{n} \cdot \mathrm{s}}$. & $.04^{\text {n.s. }}$. & $.06^{\text {n.s. }}$. & $.06^{\text {n.s. }}$. & $.14^{\star \star}$ & $.19 * \star$ & $.06^{\text {n.s. }}$. & $-.16^{\star \star}$ & - & & & \\
\hline $\begin{array}{l}10 . \\
\text { Agreeableness }\end{array}$ & 3.67 & 0.69 & $.05^{\text {n.s }}$. & $.14^{\star \star}$ & $.06^{\text {n.s }}$. & $.06^{\text {n.s }}$. & $.12^{\star \star}$ & $.14^{\star \star}$ & $.08^{\text {n.s. }}$ & $-.04^{\mathrm{n} . \mathrm{s}}$ & $.09 *$ & - & & \\
\hline $\begin{array}{l}11 . \\
\text { Neuroticism }\end{array}$ & 2.71 & 0.87 & $-.09 *$ & $-.06^{\mathrm{n} . \mathrm{s}}$ & $-.08^{\mathrm{n} . \mathrm{s}}$ & $-.07^{\mathrm{n} . \mathrm{s}}$ & $-.10^{*}$ & $-.20 * \star$ & $.02^{\text {n.s }}$ & $.12^{\star \star}$ & -.11 ** & $-.21 \star \star$ & - & \\
\hline $\begin{array}{l}12 . \\
\text { Extraversion }\end{array}$ & 3.26 & .98 & $.11^{\star}$ & $.08^{\text {n.s. }}$. & $.06^{\text {n.s }}$. & $.08^{\text {n.s }}$. & $.09 *$ & $.23^{\star \star}$ & $.09 *$ & $-.12^{\star \star}$ & $.16^{\star *}$ & $.11^{\star \star}$ & $-.16^{\star \star}$ & - \\
\hline 13. Openness & 3.75 & 0.89 & $-.02^{\mathrm{n} . \mathrm{s}}$ & $.10^{*}$ & $.11^{\star}$ & $.06^{\mathrm{n} \cdot \mathrm{s}}$. & $.09 *$ & $.15^{\star \star}$ & $.14^{\star \star}$ & $-.08^{*}$ & $.11^{\star \star}$ & $.12^{\star \star}$ & $-.11 \star \star$ & .15 \\
\hline
\end{tabular}

Note. $n=$ sample size; $M=$ mean; $S D=$ standard deviation. ${ }^{a}$ Variables $1-4$ represent experienced change in the equivalent value. ${ }^{c}$ Variables $9-13$ represent $B$ personality traits.

n.s. $p>0.05 .{ }^{*} p<0.05 .{ }^{*} p<0.01$

\section{Figures}

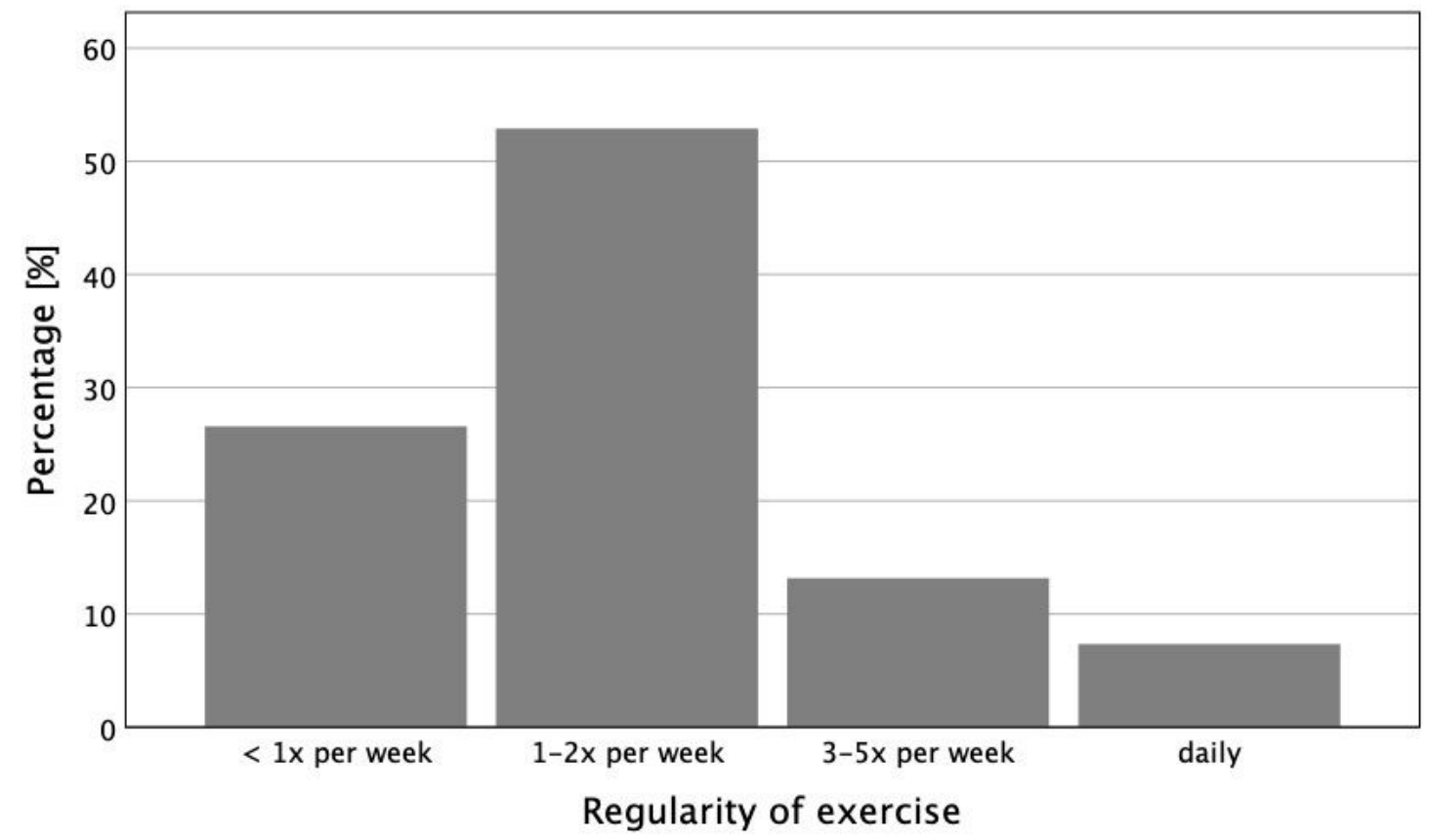

Figure 1

Regularity of Exercise on a Temporal Scale. Note. Frequency distribution of regularity of exercise in percentage.

Page 10/11 


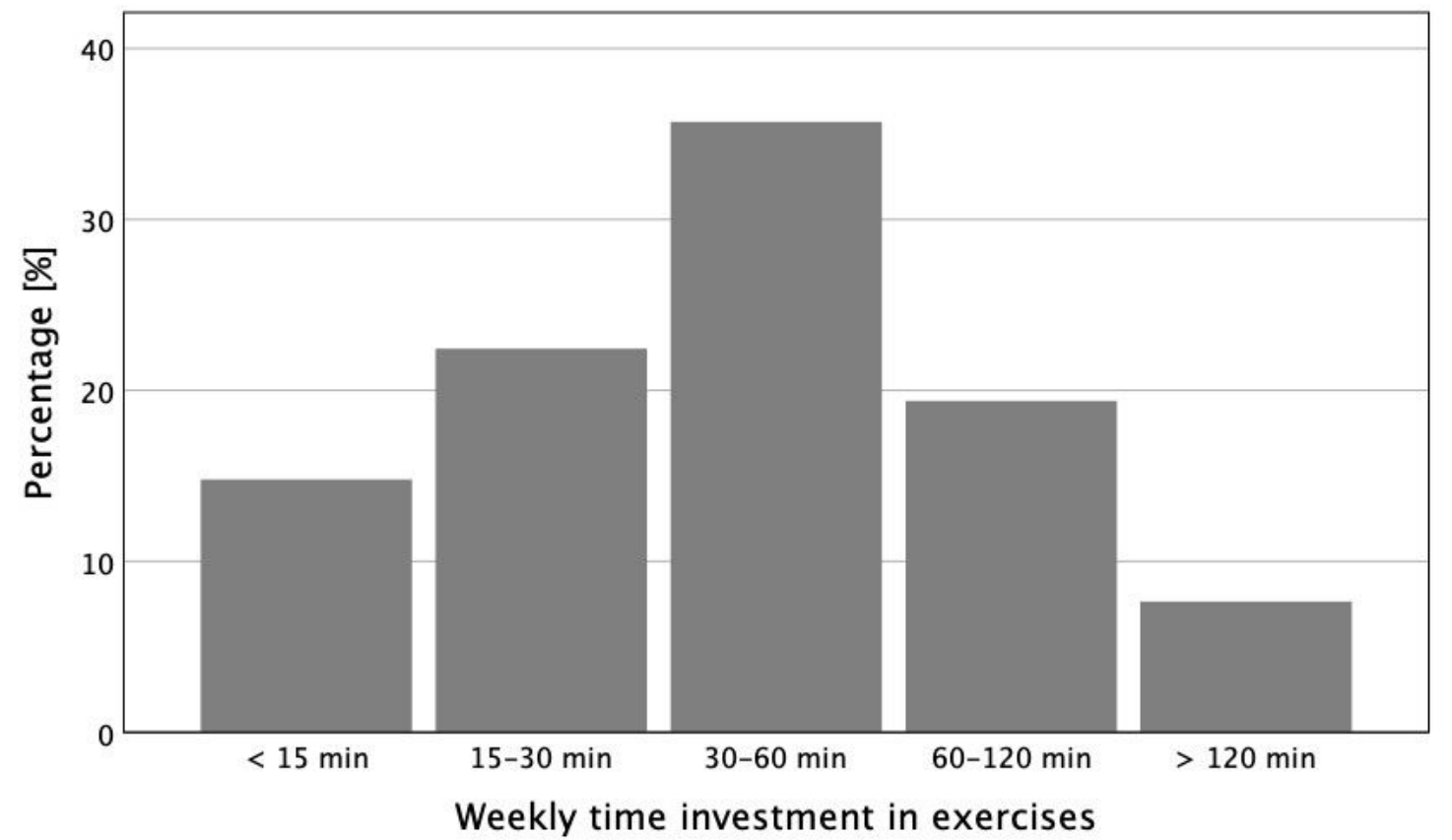

Figure 2

Weekly Time Investment in Exercise. Note. Frequency distribution of weekly time invested in exercise in percentage.

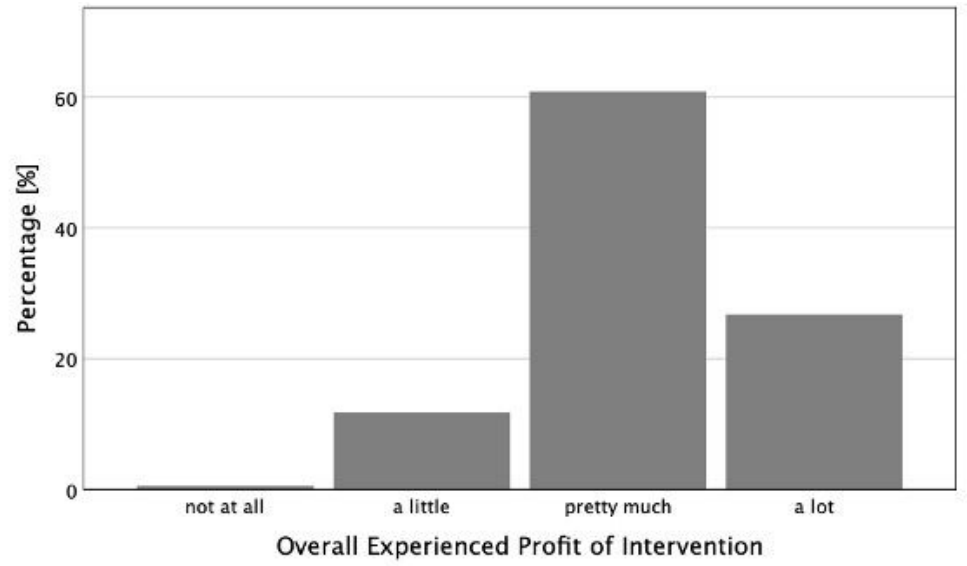

Figure 3

Overall Benefit Experienced from Intervention Represented in Verbal Categories. Note. Frequency distribution of overall benefit experienced from intervention in percentage. 